\title{
Mechanism of the Inhibition of Cholesterol Absorption by DL-Melinamide: Inhibition of Cholesterol Esterification
}

\author{
Kazuichi NATORI, Yuko OKAZAKI, Takeshi NAKAJIMA, \\ Toshiyuki HIROHASHI and Shunji AONO \\ Research Laboratories, Sumitomo Pharmaceuticals Co., Ltd.. \\ 1-98, Kasugadenaka 3-chome, Konohana-ku. Osaka 554, Japan
}

Accepted September 1.1986

\begin{abstract}
In order to elucidate the mechanism of action of DL-melinamide [DLMA, $N$ - $(\alpha$-methylbenzyl) linoleamide], an inhibitor of cholesterol absorption, the effect of DL-MA on esterification of cholesterol in the mucosa of rabbit small intestine was studied. DL-MA inhibited acyl COA:cholesterol acyltransferase (ACAT, EC 2.3.1.26) activity in the mucosal microsomes, with $50 \%$ inhibition occurring at approximately $0.5 \mu \mathrm{M}$. On the other hand. DL-MA had no effect on the cholesterol esterase (EC 3.1.1.13) activity in the mucosal cytosol. Kinetic studies indicate that DL-MA is an uncompetitive inhibitor of ACAT. D-MA, one of the two optical isomers of DL-MA, was found to be a more effective inhibitor of ACAT than L-MA, another isomer. This finding indicates that the inhibition of cholesterol absorption by DL-MA depends on the inhibition of ACAT by this compound, in view of the fact that D-MA is a more effective inhibitor of cholesterol absorption than L-MA.
\end{abstract}

It has been reported that DL-melinamide (DL-MA, Artes $\left.{ }^{\mathbb{Q}}\right), \quad \mathrm{N}$ - $(\alpha$-methylbenzyl)linoleamide, has a marked cholesterollowering and anti-atherogenic effect in several kinds of cholesterol-fed animals (14). The cholesterol-lowering effect of DL-MA is thought to be due to interference with the intestinal absorption of cholesterol, as is the case with $\beta$-sitosterol $(5,6)$, but the detailed mechanism has not yet been clarified.

Fukushima et al. (6) reported that after administering DL-MA along with $\left[{ }^{3} \mathrm{H}\right]$ cholesterol to thoracic-duct fistula rats, the total $\left[{ }^{3} \mathrm{H}\right]$ cholesterol level (free+ester) and its ester ratio (ester/total) in the lymph were markedly depressed. Considering that cholesterol is absorbed as the free form (7) and is predominantly esterified before entering the lymph (8), the findings of Fukushima et al. (6) suggest that DL-MA suppresses cholesterol absorption by inhibiting esterification of cholesterol in the intestinal mucosa.

There are two major cholesterol esterfication enzymes in the small intestine, cholesterol esterase (CEase. EC 3.1.1.13) (9) and acyl CoA:cholesterol acyltransferase (ACAT, EC 2.3.1.26) (10). However, which esterifying enzyme is responsible in vivo is still unclear (11-20). The effect of DL-MA on each of these two enzymes can be studied independently because CEase is found in the cytosol (21) while ACAT is found in the microsomes $(10,22)$.

In order to elucidate the mechanism of action of DL-MA, the present investigation was undertaken to find out the effects of DL-MA on esterification of cholesterol in the intestinal mucosa in vitro and to compare its effects with those of compound 57-118 (23) and $\beta$-sitosterol (5), inhibitors of cholesterol absorption.

\section{Materials and Methods}

Chemicals: $\left[4-{ }^{14} \mathrm{C}\right.$ ]cholesterol $(60 \mathrm{mCi}$ ) $\mathrm{mmol}$ ) and $\left[1-{ }^{14} \mathrm{C}\right]$ oleoyl $\mathrm{CoA}$ were obtained from Daiichi Pure Chemicals (Tokyo. Japan), and $\beta$-sitosterol was obtained from Nakarai Chemicals, Ltd. (Kyoto, Japan). DL-MA and two optical isomers of DL-MA (D-MA and 
L-MA) were synthesized in our laboratories. Optical rotations of these isomers were: $[\alpha]_{1,}^{26.5}=+49.4$ for the $\mathrm{D}$-isomer and $[\alpha]_{\mathrm{D}}^{26.5}=-51.4$ for the L-isomer. N-(1-oxo-9octadecenyl)-DL-tryptophan (Z) ethyl ester was synthesized in our laboratories. All other chemicals used were standard high purity materials.

Animals: Male, Japanese white rabbits (Kitayama Labs., Inc., Kyoto, Japan) weighing $2.0-2.5 \mathrm{~kg}$ were used. They were housed in cages and allowed free access to rabbit pellet chow, CR-1 (Clea Japan, Inc., Tokyo) and water for two weeks before the study.

Preparation of cytosol and microsomes: Five rabbits were used in this preparation. The microsomal and cytosol fractions from the mucosa of rabbit small intestine were isolated from a homogenate prepared in $0.154 \mathrm{M}$ phosphate buffer ( $\mathrm{pH}$ 6.2) as described by Heider et al. (23). The cytosol was used for CEase assay, and the microsomal fraction was resuspended in $0.154 \mathrm{M}$ phosphate buffer ( $\mathrm{pH} \mathrm{7.4)} \mathrm{for} \mathrm{use} \mathrm{in} \mathrm{the} \mathrm{ACAT} \mathrm{and} \mathrm{triglyceride-}$ synthesis assays.

ACAT assay: The incorporation of $\left[1-{ }^{14} \mathrm{C}\right]$ oleoyl COA into cholesteryl ester was investigated mainly by the method of Heider et al. (23). The total volume for each assay was $0.5 \mathrm{ml}$ consisting of $10 \mathrm{nmol}$ of BSA (assuming a mol wt of 60,000), 5 ul of acetone solution of each test compound, and $10 \mathrm{nmol}$ of $\left[1-{ }^{14} \mathrm{C}\right]$ oleoyl $\mathrm{COA}(6 \mathrm{mCi} /$ $\mathrm{mmol})$ in $0.154 \mathrm{M}$ phosphate buffer $(\mathrm{pH}$ 7.4). The control samples received $5 \mu$ of acetone alone. The mixture was incubated at $37^{\circ} \mathrm{C}$ for $5 \mathrm{~min}$ before the addition of the microsomal fraction $(0.05$ to $0.1 \mathrm{mg}$ of protein) to start the reaction. Then the incubation mixtures were further incubated for $4 \mathrm{~min}$ at $37^{\circ} \mathrm{C}$.

CEase assay: CEase activity was determined mainly by the method of Heider et al. (23). The volume of the mixture or preincubation was $0.75 \mathrm{ml}$ consisting of 2.0 to $3.0 \mathrm{mg}$ of cytosol protein and $5 \mu l$ of acetone solution of each test compound in $0.154 \mathrm{M}$ phosphate buffer ( $\mathrm{pH}$ 6.2). The control samples received $5 \mu l$ of acetone alone. After the mixture was incubated for $5 \mathrm{~min}$ at $37^{\circ} \mathrm{C}$. substrates and other materials were added to give final concentrations of $3.9 \mathrm{mM}\left[4-{ }^{14} \mathrm{C}\right]$ - cholesterol (0.051 $\mathrm{mCi} / \mathrm{mmol}), 11.6 \mathrm{mM}$ oleic acid, $8.2 \mathrm{mM}$ sodium taurocholate, and $3 \mathrm{mg}$ of BSA per $\mathrm{ml}$ in $1 \mathrm{ml}$ of $0.154 \mathrm{M}$ phosphate buffer $(\mathrm{pH} 6.2)$ by the addition of $0.25 \mathrm{ml}$ of the substrate mixture prepared by the method of Borja et al. (12). Then the samples were incubated for $3 \mathrm{hr}$ at $37^{\circ} \mathrm{C}$.

Assay of triglyceride-synthesis activity: The incorporation of $\left[1-{ }^{14} \mathrm{C}\right]$ oleoyl CoA into triglyceride (TG) was followed mainly by the method of Ross et al. (24). The incubation mixture consisting of $0.5 \mathrm{ml}$ of $0.154 \mathrm{M}$ phosphate buffer $(\mathrm{pH} 7.4)$ containing 10 $n$ mol of BSA, $5 \mu$ l of acetone solution of each test compound. and 0.05 to $0.1 \mathrm{mg}$ of microsomal protein was incubated at $37^{\circ} \mathrm{C}$ for $5 \mathrm{~min}$ before the addition of $10 \mathrm{nmol}$ of $\left[1-{ }^{14} \mathrm{C}\right]$ oleoyl CoA (6 $\left.\mathrm{mCi} / \mathrm{mmol}\right)$. The control samples received $5 \mu l$ of acetone alone. Then the samples were incubated at $37^{\circ} \mathrm{C}$ for $4 \mathrm{~min}$.

Assay of plasma lecithin:cholesterol acyltransferase: The activity of lecithin:cholesterol acyltransferase (LCAT, EC 2.3.1.43) was determined mainly by the method of Bell and Hubert $(25,26)$. The final volume of the incubation mixture was $0.5 \mathrm{ml}$. To $425 \mu$ of rabbit plasma, $0.2 \mathrm{mCi}$ of $\left[4-{ }^{14} \mathrm{C}\right]$ cholesterol $(60 \mathrm{mCi} / \mathrm{mmol})$ as an albumin-stabilized suspension (25) was added and permitted to equilibrate with lipoprotein cholesterol for $4 \mathrm{hr}$ at $37^{\circ} \mathrm{C}$ during which time LCAT was inhibited by 5,5-dithio-bis-2-nitrobenzoic acid $(0.7 \mathrm{mM})$. The reaction was initiated by adding $\beta$-mercaptoethanol $(12 \mathrm{mM})$ to reverse the inhibition of LCAT. Each test compound was added to the incubation mixture dissolved in acetone $(5 \mu / / 0.5 \mathrm{ml}$ of incubation mixture) immediately prior to adding $\beta$-mercaptoethanol. The control samples received $5 \mu$ of acetone alone. Then the assay mixtures were incubated at $37^{\circ} \mathrm{C}$ for $1 \mathrm{hr}$.

Analyses: Lipids were extracted with a chloroform-methanol mixture as described by Taketani et al. (27), and the extracts were fractionated by thin-layer chromatography on silica gel G-coated glass plates (Merck, Darmstadt) in a solvent system consisting of n-hexane/diethylether/acetic acid (85:15:1. $v / v / v)(24)$ in order to isolate the cholesteryl esters and triglycerides. The cholesteryl 
esters and triglycerides were visualized by exposure of the chromatograms to $I_{2}$ vapor and then scraped from the plates into vials containing $10 \mathrm{ml}$ of Scintisol AM-1 (Wako Pure Chemical Industry, Ltd., Osaka, Japan) for radioactivity assay in a Packard model TRICARB 460 CD-liquid Scintillation counter. Quench corrections were made using an external standard. Plasma free cholesterol was measured using Free Cholesterol CTest Wako (Wako Pure Chemical Industries, Ltd.).

Protein was determined by the method of Lowry et al. (28).

\section{Results}

Effect on CEase activity: No effect was found for DL-MA, $\beta$-sitosterol and 57-118 on CEase activity over the concentration range of $0.1-10 / \mathrm{M}$ (Table 1).

Effect on ACAT activity: DL-MA was shown to be a potent inhibitor of ACAT. with $50 \%$ inhibition occurring at approximately $0.5 \mu \mathrm{M}$ and $90 \%$ inhibition at $10 \mu \mathrm{M}$ (Fig. 1). $\beta$-Sitosterol inhibited ACAT activity much less effectively than DL-MA (Fig. 1. Exp. 1), while 57-118 inhibited ACAT activity in the same manner as DL-MA (Fig. 1. Exp. 2). The kinetic data with DL-MA concentrations of $O$ (control) and $0.5 \mu \mathrm{M}$ were plotted according to Lineweaver-Burk (Fig. $2)$. The apparent $K_{m}$ values were 18.8 and $3.2 / \mathrm{M}$, and the apparent $\mathrm{V}_{\max }$ values were 278 and $42 \mathrm{pmol} \cdot \mathrm{mg}$ protein ${ }^{-1} \cdot \mathrm{min}^{-1}$ at $\mathrm{DL}$ MA concentrations of 0 and $0.5 / \mathrm{M}$. respectively. These data suggest that DL-MA acts as an uncompetitive inhibitor of ACAT.

Fukushima et al. $(6,29)$ have shown that D-MA, one of the two optically active isomers of DL-MA. depresses the elevation of total cholesterol levels in the serum of cholesterolfed rabbits and rats more effectively than $L$ MA, another isomer. Therefore, in order to determine whether the inhibition of cholesterol absorption by DL-MA depends on the inhibition of ACAT activity by DL-MA, the inhibitory effect of D-MA on ACAT activity was compared with that of L-MA. The results shown in Fig. 3 indicate that the inhibitory effect of D-MA is significantly greater than

Table 1. Effect of DL-MA, $\beta$-sitosterol, and 57-118 on CEase activity in the mucosal cytosol of the rabbit small intestine

Exp. 1

\begin{tabular}{|c|c|c|}
\hline \multirow{2}{*}{ Concentration ( $\mu \mathrm{M})$} & \multicolumn{2}{|c|}{ CEase activity ( $\%$ of control) } \\
\hline & DL-MA & $\beta$-Sitosterol \\
\hline 0.1 & $106.7 \pm 0.4$ & $104.0 \pm 1.7$ \\
\hline 1.0 & $104.8 \pm 0.6$ & $104.0 \pm 2.1$ \\
\hline 3.0 & $104.5 \pm 0.8$ & $101.1 \pm 1.2$ \\
\hline 10.0 & $101.6 \pm 0.9$ & $102.9 \pm 1.0$ \\
\hline
\end{tabular}

Exp. 2

Concentration $(\mu \mathrm{M})$

CEase activity (\% of control)

$\begin{array}{rrr} & \text { DL-MA } & 57-118 \\ 0.1 & 99.0 \pm 1.2 & - \\ 1.0 & 97.9 \pm 3.2 & 92.8 \pm 1.2 \\ 3.0 & 100.2 \pm 1.3 & 94.3 \pm 0.9 \\ 10.0 & 97.4 \pm 2.1 & 98.1 \pm 0.7\end{array}$

Each compound dissolved in $5 \mu$ of acetone was added to $1.0 \mathrm{mi}$ (final volume) of the incubation mixture for CEase. The control mixtures received $5 \mu$ of acetone aione. Enzyme assays were performed as described in Methods. Reactions were initiated by the addition of the substrate mixture containing [4${ }^{14} \mathrm{C}$ ]cholesterol and oleic acid, after a 5 -min incubation of all other components at $37^{\circ} \mathrm{C}$. The values are the mean of triplicate samples \pm S.E.M. The control values in Exp. 1 and Exp. 2 were $0.96 \pm 0.01$ and $0.90 \pm 0.04 \mathrm{nmol}$ of $\left[4-^{14} \mathrm{C}\right]$ cholesteryl oleate-mg of cytosol protein ${ }^{-1} \cdot \mathrm{hr}^{-1}$, respectively. 


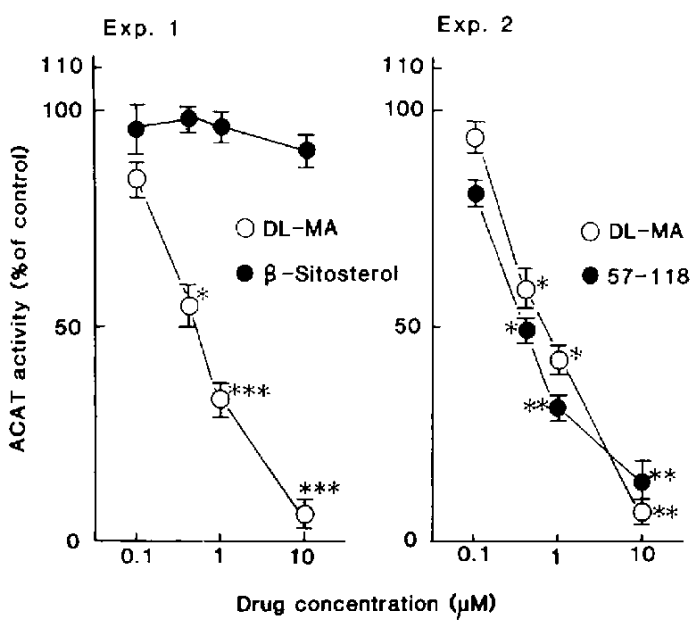

Fig. 1. Effect of DL-MA, $\beta$-sitosterol and 57-118 on ACAT activity in the mucosal microsomes of rabbit small intestine. Each compound dissolved in $5 \mu \mathrm{l}$ of acetone was added to $0.5 \mathrm{ml}$ of the incubation mixture for ACAT. The control mixtures received $5 \mu 1$ of acetone alone. Enzyme assays were performed as described in Methods. Reactions were initiated by the addition of the microsomal fraction, after a 5-min incubation of all other components at $37^{\circ} \mathrm{C}$. Each value is the mean of triplicate assays \pm S.E.M. The control values in Exp. 1 and Exp. 2 were $78.7 \pm 4.3$ and $88.3 \pm 11.8 \mathrm{pmol}$ of cholestery|[1-14 C]oleate $\cdot \mathrm{mg}$ of microsomal protein ${ }^{-1} \cdot \mathrm{min}^{-1}$, respectively. ${ }^{*} \mathrm{P}<0.05,{ }^{* *} \mathrm{P}<0.01$. ${ }^{* * *} \mathrm{P}<0.001$ vs. control.

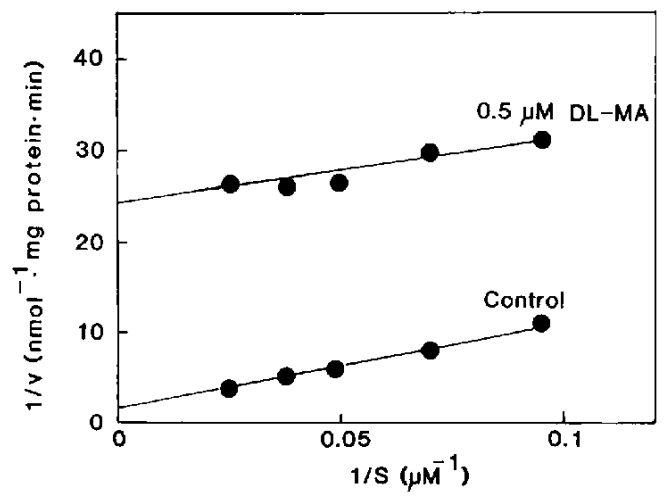

Fig. 2. Lineweaver-Burk plot of inhibition of ACAT activity by DL-MA. The enzyme assay conditions were as described in Methods except for the variations shown. Each value is the mean of triplicate assays. $v$. nmol of cholesterol[ $\left[1-{ }^{4} \mathrm{C}\right]$ oleate formed $\cdot \mathrm{mg}$ of microsomal protein ${ }^{-1} \cdot \mathrm{min}^{-1}$; s, [1${ }^{14} \mathrm{C}$ ]oleoyl-CoA $\mu \mathrm{M}$.

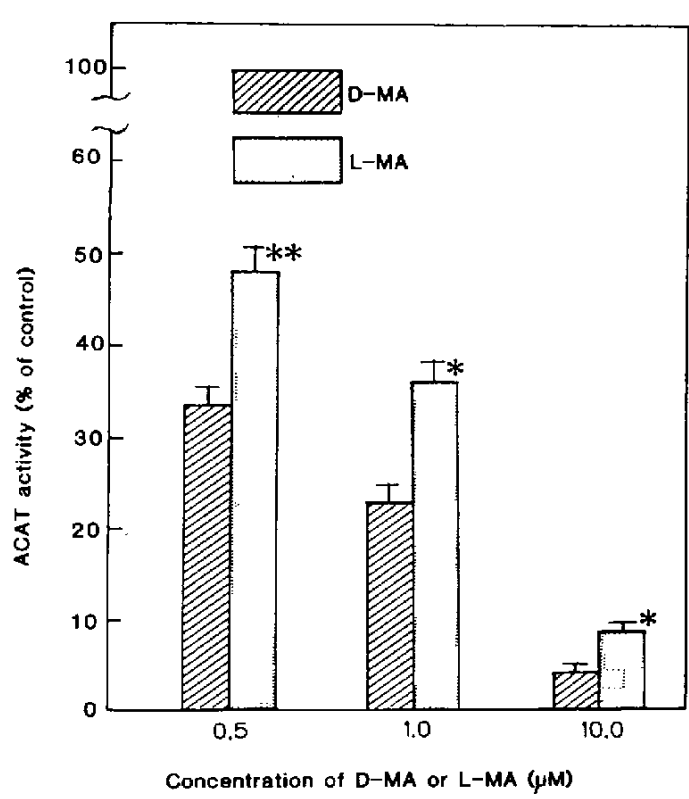

Fig. 3. Effect of D-MA and L-MA on ACAT activity. Enzyme assays were performed as described in Methods. The values are the means of triplicate samples \pm S.E.M. The control activity of ACAT was $57.2 \pm 2.3 \mathrm{pmol}$ of cholesteryl $[1-14 \mathrm{C}]$ oleate $\mathrm{mg}$ of micrasomal protein ${ }^{-1} \cdot \mathrm{min}^{-1}$. $" P<0.05,{ }^{* *} P<0.01$. compared with the corresponding values of D-MA.

that of L-MA at levels of $0.5,1.0$ and $10 \mu \mathrm{M}$.

Effect on TG-synthesis and LCAT activity: In order to determine whether DL-MA is a selective inhibitor of $\mathrm{ACAT}$, the effects of DL-MA on the TG-synthesis and LCAT activities were studied. DL-MA was shown to inhibit the TG-synthesis activity at $10 \mu \mathrm{M}$ (Fig. 4), but at least $60 \%$ activity remained at $10 \mu \mathrm{M}$ of DL-MA, which inhibited ACAT activity almost completely (Fig. 1). $\beta$ Sitosterol had a negligible effect on the TGsynthesis activity (Fig. 4. Exp. 1), and the effect of 57-118 on this activity was similar to that of DL-MA (Fig. 4, Exp. 2).

DL-MA, $\beta$-sitosterol and 57-118 had almost no effect on LCAT activity over the concentration range of $0.1-10 » \mathrm{M}$ (Fig. 5).

\section{Discussion}

The present study clearly shows that DL$M A$ is a potent and selective inhibitor of ACAT in the rabbit intestinal mucosa (Figs. 1 . 4 and 5). DL-MA is thought to inhibit in vivo 


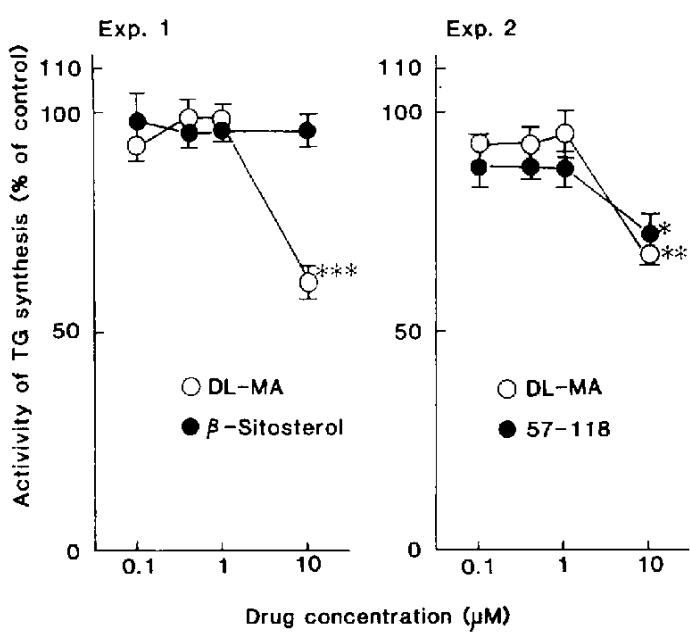

Fig. 4. Effect of DL-MA, $\beta$-sitosterol, and 57-118 on the TG-synthesis activity in the mucosal microsomes of the rabbit small intestine. Each compound dissolved in $5 \mu$ of acetone was added to $0.5 \mathrm{ml}$ of the incubation mixture for $T G$-synthesis. The control samples contained an equal volume of acetone (5 $\mu 1)$. Enzyme assays were performed as described in Methods. Reactions were initiated by the addition of $\left[1-{ }^{14} \mathrm{C}\right]$ oleoyl $\mathrm{CoA}$, after a 5 -min incubation of all other components at $37^{\circ} \mathrm{C}$. Each value is the mean of triplicate assays \pm S.E.M. The control values in Exp. 1 and Exp. 2 were $0.66 \pm 0.01$ and $0.60 \pm 0.03$ nmol $\left[1-{ }^{14} \mathrm{C}\right]$ oleoyl-CoA incorporated into $\mathrm{TG} \cdot \mathrm{mg}$ of microsomal protein ${ }^{-1} \cdot \mathrm{min}^{-1}$, respectively. ${ }^{*} \mathrm{P}<0.05$ ${ }^{* *} \mathrm{P}<0.01,{ }^{* * *} \mathrm{P}<0.001$ vs. control.

ACAT activity in the mucosa of the small intestine because about $50 \%$ of orally administered DL-MA is absorbed in rabbits (30). Moreover, the inhibitory effect of D-MA on ACAT activity is significantly greater than that of L-MA (Fig. 3). It was found that both $D-M A$ and L-MA were not metabolized in the incubation mixture in our preliminary study using ${ }^{14} \mathrm{C}$-DL-MA. (data not shown). Therefore, it may be due to the difference of the stereospecificity of these two isomers. Fukushima et al. (6) demonstrated that the inhibitory effect of D-MA on the transportation of $\left[{ }^{3} \mathrm{H}\right]$ cholesterol, administered orally, into the lymph is greater than that of L-MA in thoracic-duct fistula rats. Therefore, it is suggested that the inhibitory effect of DLMA on ACAT activity is closely related to the inhibition of cholesterol absorption by $\mathrm{DL}$ MA.

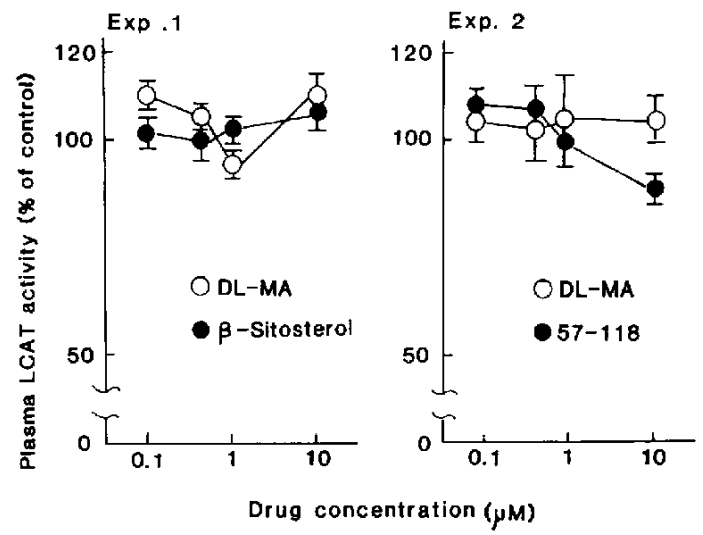

Fig. 5. Effect of DL-MA. $\beta$-sitosterol, and 57-118 on LCAT activity in rabbit plasma. LCAT activity in rabbit plasma $(425 \mu l)$ was inhibited by the addition of DTNB, and lipoprotein cholesterol was permitted to equilibrate with $\left[4-{ }^{14} \mathrm{C}\right]$ cholesterol as described in Methods. The enzyme assay conditions and chemical determination were performed as described in Methods. Reactions were initiated by adding $\beta$ mercaptoethanol to the incubation mixture to reverse the inhibition of LCAT activity. Each compound dissolved in $5 \mu \mathrm{l}$ of acetone was added to $0.5 \mathrm{ml}$ (final volume) of the incubation mixture for LCAT just prior to adding $\beta$-mercaptoethanol. The control mixtures received $5 \mu$ of acetone alone. Each value is the mean of triplicate assays \pm S.E.M. The control values in Exp. 1 and Exp. 2 were $65.9 \pm 4.4$ and $57.2 \pm 4.4 \mathrm{pmol}$ of $\left[4-{ }^{14} \mathrm{C}\right]$ cholesterol ester formed. $\mathrm{ml}$ of plasma $^{-1} \cdot \mathrm{min}^{-1}$, respectively.

$\beta$-Sitosterol has almost no ability to inhibit ACAT activity as compared with DL-MA (Fig. 1). This finding supports the work of Field and Mathur (31) who showed that $\beta$ sitosterol does not interfere with nor compete with the esterification of cholesterol via ACAT. Therefore, it is suggested that $\beta$ sitosterol inhibits cholesterol absorption by mechanisms other than inhibition of ACAT activity. For example, the restriction of the micellar solubility of cholesterol by $\beta$ sitosterol in the intestinal lumen is proposed as a possible mechanism (32).

Recently, two long chain fatty acylamides were reported to inhibit both cholesterol absorption and ACAT activity. One is compound 57-118 which was reported by Heider et al. (23). They demonstrated that $57-118$ inhibits cholesterol absorption in cholesterol- 
fed rabbits and that this effect is correlated with the inhibition of ACAT activity in the intestinal mucosa. Our present data (Fig. 1. Exp. 2) confirm the inhibitory effect of 57 118 on ACAT activity observed by $\mathrm{Heider}$ et al. (23). DL-MA is similar to 57-118 with regard to the ability to inhibit both cholesterol absorption and ACAT activity. Furthermore, these two compounds have a similar chemical structure: long chain fatty acylamide. However, they have some different features. DL-MA is an uncompetitive inhibitor of ACAT, while $57-118$ is a competitive inhibitor (23).

Another acylamide is compound 58-035. 3-(decyldimethy|silyl) - N- [2-(4-methylphenyl)-1-phenylethyl] propanamide, which was studied by Ross et al. (24) and Clark and Tercyak (33). Ross et al. demonstrated that 58-035 is a potent inhibitor of ACAT in the microsomes of both rat liver and hepatoma cells, while it has a negligible effect on both acyl CoA:retinol acyltransferase and TGsynthesis activity. Furthermore, Clark and Tercyak (33) demonstrated that 58-035 greatly reduces the secretion of total cholesterol into the mesenteric lymph and its ester ratio in rats. Fukushima et al. (6) reported the same effect of DL-MA on the secretion of total cholesterol into the lymph and its ester ratio as that of 58-035.

The findings described above suggest that these three acylamides, DL-MA, 57-118. and 58-035, have a common action: inhibition of the transportation of total cholesterol into the mesenteric lymph by inhibiting ACAT activity in the intestinal mucosa. Therefore, it should be very interesting to clarify the relationship between the chemical structure of various acylamides and the inhibitory effects of these compounds on ACAT activity. Extensive studies on this problem are now in progress.

Acknowledgement: We thank Dr. Takenari Nakagome and Dr. Junki Katsube for helpful discussion and encouragement throughout this work.

\section{References}

1 Toki, K., Fukumaru, T., Nakatani, H. and Fukushima, $\mathrm{H}$ :: The prevention of experimental atherosclerosis by a novel linoleic acid derivative. J. Atheroscler. Res. 7, 708-710 (1967)
2 Fukushima, H., Aono, S. and Nakatani, H.: Effect of $N$ - $(\alpha$-methylbenzyl)linoleamide on lipid levels of plasma and liver in cholesterol-fed rats. U. Nutr. 96, 15-20 (1968)

3 Fukushima, $\mathrm{H}$., Toki, $\mathrm{K}$ and Nakatani, $\mathrm{H}$.: The effect of $N$ - $(\alpha$-methylbenzyl)linoleamide on experimental atherosclerosis in rabbits. J. Atheroscler. Res. 9, 57-64 (1969)

4 Fukushima, H., Aono, S. and Nakatani, H: Cholesterol-lowering effects of amide derivatives of linoleic acid in chickens and mice. J. Pharm. Soc. Japan 89, 857-862 (1969) (Abs. in English)

5 Shidoji, Y., Watanabe, M., Oku, T., Muto, Y. and Hosoya, $\mathbf{N}$ : Inhibition of $\beta$-sitosterol in intestinal cholesterol absorption in rat using in vivo dual isotope ratio method. J. Nutr. Sci. Vitaminol. 26, 183-188 (1980)

6 Fukushima, H., Aono, S., Nakamura, Y., Endo, $M$. and Imai, T.: The effect of $N-(\alpha-$ methylbenzyl)linoleamide on cholesterol metabolism in rats. J. Atheroscler. Res. 10, 403-414 (1969)

7 Shiratori, T. and Goodman, D.S.: Complete hydrolysis of dietary cholesterol esters during intestinal absorption. Biochim. Biophys. Acta 106, 625-627 (1965)

8 Vahouny, G.V. and Treadwell, C.R.: Changes in lipid composition of lymph during cholesterol absorption in the rat. Am. J. Physiol. 191, 179 184 (1957)

9 Swell, L., Byron, J.E. and Treadwell, C.R.: Cholesterol esterases. IV. Cholesterol esterase of rat intestinal mucosa. J. Biol. Chem. 186, 543-548 (1950)

10 Haugen, R. and Norum, K.R.: Coenzyme Adependent esterification of cholesterol in rat intestinal muccsa. Scand. J. Gastroenterol. 11, 615-621 (1976)

11 Swell, L., Trout, E.C., Hopper, R., Field, H. and Treadwell, C.R.: The mechanism of cholesterol absarption. Ann. N.Y. Acad. Sci. 72, 813-825 (1959)

12 Borja, C.R., Vahouny, G.V. and Treadwell, C.R.: Role of bile and pancreatic juice in cholesterol absorption and esterification. Am. J. Physiol. 206, 223-228(1964)

13 Gallo, L.L., Newbill, T., Hyun, J., Vahouny, G.V. and Treadwell, C.R.: Role of pancreatio cholesterol esterase in the uptake and esterification of cholesterol by isolated intestinal celis. Proc. Soc. Exp. Biol. Med. 156, 277-281 (1977)

14 Gallo, L.L., Chiang, Y., Vahouny, G.V. and Treadwell, C.R.: Localization and origin of rat intestinal cholesterol esterase determined by immunocytochemistry. J. Lipid Res. 21, 537-545 
(1980)

15 Norum, K.R., Lilljeqvist, A.C., Helgerud, P., Norman, E.R., Mo, A. and Selbekk, B.: Esterification of cholesterol in human small intestine: and importance of acyl-CoA: cholesterol acyltransferase. Eur. J. Clin. Invest. 9, 55-64 (1979)

16 Clark, S.B.: Mucosal coenzyme A-dependent cholesterol esterification after intestinal perfusion of lipids in rats. J. Biol. Chem. 254, 1534-1536 (1979)

17 Helgerud, P., Saarem, K. and Norum, K.R.: Acyl-CoA: cholesteral acyltransferase in human small intestine: its activity and some properties of the enzymatic reaction. J. Lipid Res. 22, $271-277$ (1981)

18 Norum, K.R., Helgerud, P. and Lilljequist, A.C.: Enzymatic esterification of cholesterol in rat intestinal mucosa catalyzed by acyi-CoA: cholesterol acyltransferase. Scand. J. Gastroenterol. 16, 401-410 (1981)

19 Helgerud, P., Haugen, R, and Norum, K.R.: The effect of feeding and fasting on the activity of acyl-CoA:cholesterol acyltransferase in rat small intestine. Eur. J. Clin. Invest. 12, 493-500 (1982)

20 Field, F.J., Cooper, A.D. and Erickson, S.K.: Regulation of rabbit intestinal acyl coenzyme $A$ : cholesterol acyltransferase in vivo and in vitro. Gastroenterology 83, 873-880 (1982)

21 Gallo, L.L. and Treadwell, C.R.: Localization of cholesterol esterase and cholesterol in mucosal fractions of rat small intestines. Proc. Soc. Exp. Biol. Med. 114, 69-72 (1963)

22 Norum, K.R., Lilljeqvist, A.C. and Drevon, C.A.: Coenzyme-A-dependent esterification of cholesterol in intestina! mucosa from guinea pigs: Influence of diet on the enzyme activity. Scand. J. Gastroenterol. 12, 281-288 (1977)

23 Heider, J.E., Pickens, C.E. and Kelly, L.A.: Role of acyl CoA:cholesterol acyltransferase in cholesterol absorption and its inhibition by $57-$ 118 in the rabbit. J. Lipid Res. 24, 1127-1134
(1983)

24 Ross, A.C., Go, K.J., Heider, J.G. and Rothblat, G.H.: Selective inhibition of acyl Coenzyme A: cholesterol acyltransferase by compound 58035. J. Biol. Chem. 259, 815-819 (1984)

25 Bell, F.P. and Hubert, E.V.: Lecithin-cholesterol acyltransferase: inhibition by local anesthetics in plasma from man and experimental animals in vitro. Lipids 15, 811-814 (1980)

26 Bell, F.P. and Hubert, E.V.: Inhibition of LCAT in plasma from man and experimental animals by chlorpromazine. Lipids 16, 815-819 (1981)

27 Taketani, S., Nishino, T. and Katsuki, H.: Characterization of sterol-ester synthetase in Saccharomyces cerevisie. Biochim. Biophys. Acta 575, 148-155 (1979)

28 Lowry, O.H., Rosebrough, N.J., Farr, A.L. and Randall, R.J.: Protein measurement with Folin phenol reagent. J. Biol. Chem. 193, 265-275 (1951)

29 Fukushima, H. and Nakatani, H.: Cholesterollowering effects of DL-N-( $\alpha$-methylbenzyl) linoleamide and its optically active isomers in cholesterol-fed animals. J. Atheroscler. Res. 9, 65-71 (1969)

30 Fukushima, H.: Absorption, tissue distribution, and excretion of $\mathrm{N}-(\alpha$-methylbenzyl $)$ linoleamide. Pharmacometrics. 3, 135-140 (1969)

31 Field, F.J. and Mathur, S.N.: $\beta$-Sitosterol: esterification by intestinal acylcoenzyme $A$ : cholesterol acyltransferase (ACAT) and its effect on cholesterol esterification. J. Lipid Res. 24, 409-417 (1983)

32 Ikeda, I. and Sugano, M.: Some aspects of mechanism of inhibition of cholesterol absorption by $\beta$-sitosterol. Biochim. Biophys. Acta $732,651-658$ (1983)

33 Clark, S.B. and Tercyak, A.M.: Reduced cholesterol transmucosal transport in rats with inhibited mucosal acyl CoA-cholesterol acyltransferase and normal pancreatic function. J. Lipid Res. 25, 148-159 (1984) 